\title{
Optimisation of Parboiling Process using Response Surface Methodology (RSM) to improve the Physical Properties of Parboiled Milled Rice
}

\author{
${ }^{1}$ Ogunbiyi, M. O., \\ ${ }^{1}$ Department of Agribusiness and Market Development, \\ Federal Ministry of Agriculture and Rural Development,
} Abuja, Nigeria

\author{
${ }^{2}$ Adejumo, B. A., ${ }^{2}$ Gbabo, A. \\ ${ }^{2}$ Department of Agricultural and Bioresources Engineering, \\ Federal University of Technology, Minna, Nigeria
}

\author{
${ }^{3}$ Chinma, C. E. \\ ${ }^{3}$ Department of Food Science and Technology, \\ Federal University of Technology, Minna, Nigeria
}

\begin{abstract}
The optimisation of the parboiling conditions of a popular rice variety in Nigeria using Response Surface Methodology (RSM) was carried out. The parboiling conditions Initial Soaking Temperature (IST), Soaking Time (ST) and Final Moisture Content (FMC) were statistically combined in a Central Composite Design (CCD) with the effects on selected physical properties of milled rice of FARO 52 rice variety determined. Results obtained were analysed to determine the optimum parboiling conditions (OPC) to produce milled rice with improved physical qualities. Results showed significant influence (at $95 \%$ confidence level) of IST, ST and FMC on the head rice yield, broken rice ratio, grain hardness and grain colour of the parboiled milled rice. The optimum paddy parboiling conditions for improved physical qualities of milled rice are: Initial soaking temperature: $67.7^{\circ} \mathrm{C}$; Soaking time: $13 \mathrm{hrs}$ 18minutes and Final moisture content prior to milling: $12.7 \%$. These optimal conditions are expected to produce parboiled milled rice with the following physical characteristics: Head rice yield, 70\%; Broken rice ratio, 2.18\%; Grain hardness, $74.7 \mathrm{~N}$ and Grain colour, 25.8 with a composite desirability of $76.3 \%$.
\end{abstract}

Keywords- Soaking time, soaking temperature, moisture content, head rice yield, broken rice ratio.

\section{INTRODUCTION}

Rice is one of the staple food consumed Sub-Saharan Africa especially in most part of West Africa [1]. It is however a strategic commodity and a policy crop in the Nigerian economy. Rice can easily be prepared and consumed in various ways hence it is a regular item in most diets [2]. Rice is the fastest growing commodity in Nigeria's food basket and its demand has considerably increased over the years due to increase in population, urbanization and attendant shift in consumers' preference [3].

Two types of rice have been mainly cultivated in Nigeria: the African rice (Oryza glaberrima) and the Asian rice (Oryza sativa). However, other improved varieties have been developed over the years from these two major rice types. These include the West African Rice Development Association (WARDA) hybrid rice varieties referred to as New Rice for Africa: NERICA 19, NERICA 34 and NERICA 49 and Federal Agriculture Research Oryza: FARO 44, FARO 52, FARO 60, FARO 50 and other varieties.
Nigeria being a multi-ethnic nation has a variety of food cultures and tastes, but it citizens still share in common, a preference for whole kernel, polished, parboiled long-grain rice, free from stone and other foreign matter, fluffy and tender when cooked [4] [5] [6]. The affinity and consumers' acceptability as well as choice of rice in Nigeria are greatly influenced by the eating and cooking qualities which are mainly controlled by the physicochemical and cooking properties of the rice grain [6] [7] [8]. This explains why imported parboiled rice is preferred against the locally processed rice by Nigerians as imported rice show more high consistency in terms of the desirable quality attributes [7].

The parboiling process as practiced in Nigeria is not standardized and official parboiling manuals are not available. Hence, the procedure is not uniformly carried out and depends on the method prevalent in the locality and on the experience of the processor. This has resulted to the non-uniformity in the quality of parboiled milled rice produced in Nigeria. Parameters such as the initial soaking temperature and soaking time are important factors in rice parboiling and significantly affect the quality of milled parboiled rice [9]. Improper soaking at low temperature causes microbial contamination while soaking at high temperature results in sloughing-off of the surface before effective hydration is achieved [9]. Prolonged soaking results in leaching loss, fermentation, kernel bursting and colour change [10].

The quality of milled rice is determined by its physical, chemical and cooking properties [8]. The physical characteristics of the milled rice grains play a very important role in determining its market value. Such characteristics like head rice yield, broken rice ratio, grain hardness and grain colour are major determinants of the acceptability of milled rice by consumers [7]. Grain quality differs according to the varietal composition and the method of postharvest paddy handling, especially paddy parboiling, greatly influences the overall quality of the parboiled milled grain [8]. Some quality characteristics are directly determined by the variety which also interacts with environment and processing activities to influence other characteristics indirectly. 
The Response Surface Methodology (RSM) has been used by many researchers to optimize scientific processes and have been found to be very useful and efficient [11] [12]. RSM is essentially useful in experimental design to evaluate responses to independent variables in an experimental process. The methodology combines both mathematical and statistical approaches to determine the optimal conditions at which the process will produce the best responses. The objective of this study is therefore to determine the optimum conditions (initial soaking temperature, soaking time and final moisture content) for paddy parboiling to produce milled rice with improved physical qualities..

\section{MATERIALS AND METHODS}

This study was conducted at the Rice Postharvest Laboratory of the Federal Ministry of Agriculture and Rural Development, Abuja, Nigeria. A hundred kilogram $(100 \mathrm{~kg})$ sample of FARO 52 an improved high yielding irrigated rice variety commonly grown in Nigeria, was obtained from the National Cereals Research Institute (NCRI), Badeggi, Niger State, Nigeria and used for this study. Foreign matters such as stones, straw/chaff and other impurities and contaminants were removed from the sample.

\section{A. Experimental Design}

This study used Response Surface Methodology (RSM) combined with Central Composite Design (CCD) to investigate the effects of three identified factors: initial soaking temperature, soaking time and final moisture content prior to milling on the response of paddy to parboiling process. Based on reports in literature and the results of a preliminary study by the author, the following test values of the factors were selected for the study: Initial soaking temperature: $650 \mathrm{C}, 700 \mathrm{C}$ and 750C; Soaking time: 8 Hours, 12 Hours and 16 Hours and Final moisture content: $12 \%, 13.5 \%$ and $15 \%$.

A CCD with three factors at five levels was adopted for this study. MINITAB 16 Statistical software (Minitab Inc., USA) was used to design the experiments and to analyse the results. The design consisted of 20 experimental runs calculated as $2 \mathrm{k}$ $+2 k+6$ comprising of 8 cube points, 6 axial (star) points and 6 centre points; $k$ is the total number of factors [11]. The experimental range and levels of the factors are shown in Table 1 and the outline of the experimental design with coded and uncoded values is shown in Table 2 .

\section{B. Paddy parboiling, Drying and Milling}

The cleaned samples were parboiled using the laboratory mini rice parboiler [13]. Five hundred grams (500g) paddy, held in wire mesh basket, was soaked at $75^{\circ} \mathrm{C}$ for 12 hours in the soaking/steaming chamber of the parboiling equipment according to the method described by [13]. The soaked paddy samples were thereafter withdrawn from the parboiler, allowed to stand for 15 minutes for water to drain off and steamed for 35 minutes. The steamed paddy was uniformly dried in thin layer under shade in the laboratory [14]. Husking and milling of the dry parboiled paddy were done with Test Husker (Satake Corporation, Hiroshima, Japan) and Test Mill (Satake Corporation, Hiroshima, Japan) respectively.

TABLE 1. EXPERIMENTAL RANGE AND LEVELS OF THE FACTORS
\begin{tabular}{|c|c|c|c|c|c|}
\hline \multirow{2}{*}{ Factor } & \multicolumn{5}{|c|}{ Coded levels } \\
\cline { 2 - 6 } & $-\alpha$ & Low & Medium & High & $+\alpha$ \\
\cline { 2 - 6 } & -1.68 & -1 & 0 & 1 & +1.68 \\
\hline IST $\left({ }^{\circ} \mathrm{C}\right)$ & 61.59 & 65 & 70 & 75 & 78.40 \\
\hline ST (Hours) & 5.3 & 8 & 12 & 16 & 18.7 \\
\hline FMC $(\%)$ & 10.9 & 12 & 13.5 & 15 & 16.0 \\
\hline
\end{tabular}
IST=Initial Soaking Temperature, ST = Soaking Time, and FMC= Final Moisture Content.

TABLE 2. FACTORS WITH CODED AND NATURAL VALUES

\begin{tabular}{|c|c|c|c|c|c|c|}
\hline \multirow{2}{*}{ Run } & \multicolumn{3}{|c|}{$\begin{array}{c}\text { Coded form of Independent } \\
\text { variables }\end{array}$} & \multicolumn{3}{c|}{ Actual form of Independent } \\
& variables \\
\hline & $X_{1}$ & $X_{2}$ & $X_{3}$ & $X_{1}$ & $X_{2}$ & $X_{3}$ \\
\hline 1 & -1 & -1 & -1 & 65 & 8 & 12 \\
\hline 2 & 1 & -1 & -1 & 75 & 8 & 12 \\
\hline 3 & -1 & 1 & -1 & 65 & 16 & 12 \\
\hline 4 & 1 & 1 & -1 & 75 & 16 & 12 \\
\hline 5 & -1 & -1 & 1 & 65 & 8 & 15 \\
\hline 6 & 1 & -1 & 1 & 75 & 8 & 15 \\
\hline 7 & -1 & 1 & 1 & 65 & 16 & 15 \\
\hline 8 & 1 & 1 & 1 & 75 & 16 & 15 \\
\hline 9 & -1.68 & 0 & 0 & 61.59 & 12 & 13.5 \\
\hline 10 & +1.68 & 0 & 0 & 78.40 & 12 & 13.5 \\
\hline 11 & 0 & -1.68 & 0 & 70 & 5.27 & 13.5 \\
\hline 12 & 0 & +1.68 & 0 & 70 & 18.72 & 13.5 \\
\hline 13 & 0 & 0 & -1.68 & 70 & 12 & 10.98 \\
\hline 14 & 0 & 0 & +1.68 & 70 & 12 & 16.02 \\
\hline 15 & 0 & 0 & 0 & 70 & 12 & 13.5 \\
\hline 16 & 0 & 0 & 0 & 70 & 12 & 13.5 \\
\hline 17 & 0 & 0 & 0 & 70 & 12 & 13.5 \\
\hline 18 & 0 & 0 & 0 & 70 & 12 & 13.5 \\
\hline 19 & 0 & 0 & 0 & 70 & 12 & 13.5 \\
\hline 20 & 0 & 0 & 0 & 70 & 12 & 13.5 \\
\hline & $X_{l}=$ Initial Soaking Temperature, $X_{2}=$ Soaking Time, $X_{3}=$ Final Moisture Content. \\
\hline
\end{tabular}

\section{Parboiling process optimization and model development}

The data obtained from the Central Composite Design (CCD) for three factors and five level combinations were subjected to regression analysis using Response Surface Methodology (RSM), to determine the optimum conditions of the investigated independent variables (Initial soaking temperature, Soaking time and Final moisture content) for parboiling of paddy rice to produce the desired physical qualities milled rice. The models of the response factors (Yi) were developed as a mathematical function of the independent variables through the regression analysis of the experimental result data [15]. Each response (Yi) was represented by a mathematical equation that correlates the response surfaces as follows:

$$
Y=\beta_{0}+\sum_{i=1}^{k} \beta_{i} X_{I}+\sum_{i=1}^{k} \beta_{i i} X_{i}^{2}+\sum_{i=1}^{k} \sum_{i=1}^{k} \beta_{i j} X_{i} X_{j}+\varepsilon
$$


Where $\mathrm{Y}$ is the predicted response, $\mathrm{k}$ is the number of independent variables (factors) $\mathrm{Xi}(\mathrm{i}=1,2,3)$; while $\beta$ is a constant and regression coefficients of the model $(\beta \mathrm{i}, \beta \mathrm{ii}$ and $\beta \mathrm{ij}$ are the coefficient of linear, square and interaction terms respectively) and $\varepsilon$ is the random error term.

To determine if the models developed correctly describe the experimental data, the significance of the models were tested and confirmed through the estimation of the F-ratio through the ANOVA test. The models were examined for lack of fit and the coefficients of determination, $\mathrm{R}^{2}$ were also checked. The adequacy of the model was also checked with the pattern of the points on the normal probability plot of the residuals and the plots of the residuals versus the predicted response. The adequacy is confirmed when the pattern of the points on the normal probability plot forms a straight line and the plot of the residuals versus the fitted values is scattered and has no structured pattern [10].

\section{Laboratory analysis of samples}

1) Head rice yield: Milled rice grains longer than three quarters of the whole kernel classified as whole grains, were separated automatically using a cylinder-type Test Rice Grader TRG 05B (Satake Corporation, Hiroshima, Japan) [16]. The whole grains were collected and weighed. Head rice yield was calculated as the ratio of the weight of whole grain to the weight of the dry parboiled samples as follows:

$$
H R Y=\frac{\text { Weight of whole grain rice }}{\text { Weight of dry parboiled paddy }} X 100
$$

2) Broken rice ratio: The broken rice was collected from the Test Rice Grader and the broken rice ratio (BRR) was also determined in similar manner as the HRY as follows:

$$
B R R=\frac{\text { Weight of broken rice }}{\text { Weight of dry parboiled paddy }} X 100
$$

3) Grain hardness: Five whole grains randomly selected from a sample were placed on a flat plate of Hardness Tester (Fujiwara Seisakusho Ltd. Japan) and compressed until rupture. The force at rupture measured in Newtons $(\mathrm{N})$ was recorded as the hardness.

4) Grain colour: The colour of the grain was determined using a Rice Whiteness Tester C-600 (Kett Electric Laboratory, Japan). The equipment was first calibrated against a standard pure white plate of 85.5 whiteness value. The whiteness test was replicated thrice and the mean value was recorded as the colour value.

\section{RESULTS AND DISCUSSION}

\section{A. Model development}

Paddy parboiling has been reported to significantly increase head rice yield, reduce broken rice ratio and increase the nutritional content [9] [10]. Parboiling also offers higher milling recovery and produces more translucent milled rice kernels [17]. A number of factors affect the physical properties of milled rice during the parboiling process. This study however focused on three factors; initial soaking temperature, soaking time and final moisture content.
The results of the regression analysis, the polynomial equation proposed models for head rice yield (HRY), broken rice ratio (BRR), grain hardness (GH) and grain colour (GC) and the corresponding coefficients of regression $\mathrm{R}^{2}$ and $\mathrm{R}^{2}$ (adjusted) are presented in Table 3 . The observed responses and the predicted values of the physical properties are shown in Table 4.

\section{B. Test of significance and adequacy of the models}

1) Head rice yield: The linear terms in the model fitted for HRY as affected by Initial soaking temperature (IST), Soaking time (ST) and Final moisture content (FMC) are positive except the initial soaking temperature indicating that increase in the soaking time (ST) and final moisture content (FMC) will lead to increase in the HRY. There are also positive interactive effects of the initial soaking temperature and soaking time $\left(\mathrm{X}_{1} \mathrm{X}_{2}\right)$ and soaking time and final moisture content $\left(\mathrm{X}_{2} \mathrm{X}_{3}\right)$ on the HRY. Examination of the observed HRY and the predicted values of the HRY (Table 4) show that there are little variations. This confirms that the model can sufficiently predict the HRY for the parboiling factors [11]. The adequacy of the model was further confirmed by the Coefficients of Correlation $\mathrm{R}^{2}$ and $\mathrm{R}^{2}$ (adjusted) values of 0.98 and 0.96 respectively. These coefficients which are between 0 and 1 should be close to unity [10]. The p-value for all the terms also showed significance at $95 \%$ confidence level. The large F-ratio as shown in the Analysis of variance (ANOVA) in Table 5 and the p-value for all the terms in the model which showed significance at $95 \%$ confidence level also confirmed the significance of the model. The normal probability plot of the residuals as shown in Figure 1 formed a linear graph (straight line) indicating that neither response transformation was required nor there was any apparent problem with normality assumption of the regression model [10] [18]. The plot of the residuals versus the predicted response (Figure 2) is scattered and showed no structured pattern. This further confirmed the adequacy of the model for HRY described in Table 3.

2) Broken rice ratio: The model fitted for BRR showed the linear terms except that of the soaking time are positive (Table 3). This indicated that increase in the soaking time (ST) may lead to the reduction of percentage of broken rice after milling the paddy. However, increase in the Initial soaking temperature and Final moisture content of the parboiled paddy may cause a corresponding increase in the broken rice ratio. The significance of the individual terms of the model from the ANOVA is shown in Table 6. The adequacy of the model is confirmed by R2 and R2 (adjusted) values of 0.84 and 0.70 respectively. Also, the normal probability plot of the residuals formed a linear graph and the plot of the residuals versus the predicted response showed a scattered pattern. The p-value for the linear and interaction terms showed significance at $95 \%$ confidence level. 
TABLE 3. POLYNOMIAL EQUATION PROPOSED MODELS FOR PHYSICAL PROPERTIES AND REGRESSION COEFFICIENTS FOR THE DEVELOPED MODELS

\begin{tabular}{|c|c|c|c|}
\hline \multirow[t]{2}{*}{ Response } & \multirow[t]{2}{*}{ Regression Equation } & \multicolumn{2}{|c|}{ Regression Coefficient } \\
\hline & & $\mathrm{R}^{2}$ & $\mathrm{R}^{2}$ (adjusted) \\
\hline HRY & $\begin{array}{c}\mathrm{Y}=70.29-0.311 \mathrm{X}_{1}+1.09 \mathrm{X}_{2}+0.23 \mathrm{X}_{3}-0.28 \mathrm{X}_{1}^{2}-0.49 \mathrm{X}_{2}^{2}-0.91 \mathrm{X}_{3}^{2}+0.4 \mathrm{X}_{1} \mathrm{X}_{2}- \\
0.33 \mathrm{X}_{1} \mathrm{X}_{3}+0.75 \mathrm{X}_{2} \mathrm{X}_{3}\end{array}$ & 0.98 & 0.96 \\
\hline BRR & $\begin{array}{c}\mathrm{Y}=2.292+0.09 \mathrm{X}_{1}-0.33 \mathrm{X}_{2}+0.003 \mathrm{X}_{3}-0.034 \mathrm{X}_{1}^{2}+0.16 \mathrm{X}_{2}^{2}+0.09 \mathrm{X}_{3}^{2}-0.21 \mathrm{X}_{1} \mathrm{X}_{2} \\
-0.19 \mathrm{X}_{1} \mathrm{X}_{3}-0.113 \mathrm{X}_{2} \mathrm{X}_{3}\end{array}$ & 0.84 & 0.70 \\
\hline GH & $\begin{array}{c}\mathrm{Y}=73.78-0.71 \mathrm{X}_{1}+3.67 \mathrm{X}_{2}-0.37 \mathrm{X}_{3}+4.18 \mathrm{X}_{1}^{2}-3.74 \mathrm{X}_{2}^{2}-2.5 \mathrm{X}_{3}^{2}-4.08 \mathrm{X}_{1} \mathrm{X}_{2} \\
+2.45 \mathrm{X}_{1} \mathrm{X}_{3}+0.25 \mathrm{X}_{2} \mathrm{X}_{3}\end{array}$ & 0.94 & 0.89 \\
\hline $\mathrm{GC}$ & $\begin{array}{c}\mathrm{Y}=25.91+0.08 \mathrm{X}_{1}-0.39 \mathrm{X}_{2}-0.02 \mathrm{X}_{3}-0.25 \mathrm{X}_{1}^{2}-0.27 \mathrm{X}_{2}^{2}-0.06 \mathrm{X}_{3}^{2}-0.038 \mathrm{X}_{1} \mathrm{X}_{2}+ \\
0.26 \mathrm{X}_{1} \mathrm{X}_{3}-0.29 \mathrm{X}_{2} \mathrm{X}_{3}\end{array}$ & 0.89 & 0.79 \\
\hline
\end{tabular}

$\mathrm{HRY}=$ Head rice yield; $\mathrm{BRR}=$ Broken rice ratio; $\mathrm{GH}=$ grain hardness $; \mathrm{GC}=$ Grain colour $\mathrm{X}_{1}=$ Initial Soaking Temperature, $\mathrm{X}_{2}=$ Soaking Time, $\mathrm{X}_{3}=$ Final Moisture Content

TABLE 4. OBSERVED AND PREDICTED VALUES FOR THE PHYSICAL CHARACTERISTICS OF MILLED RICE

\begin{tabular}{|c|c|c|c|c|c|c|c|c|}
\hline \multirow[t]{2}{*}{ Run } & \multicolumn{2}{|c|}{$\begin{array}{c}\text { Head Rice Yield } \\
(\%)\end{array}$} & \multicolumn{2}{|c|}{$\begin{array}{c}\text { Broken Rice Ratio } \\
(\%)\end{array}$} & \multicolumn{2}{|c|}{$\begin{array}{l}\text { Hardness } \\
(\mathrm{N})\end{array}$} & \multicolumn{2}{|c|}{$\begin{array}{c}\text { Colour (Whiteness } \\
\text { value) }\end{array}$} \\
\hline & Observed & Predicted & Observed & Predicted & Observed & Predicted & Observed & Predicted \\
\hline 1 & 68.30 & 68.42 & 2.10 & 2.25 & 60.80 & 59.40 & 25.60 & 25.60 \\
\hline 2 & 67.90 & 67.65 & 3.30 & 3.22 & 62.40 & 61.23 & 25.00 & 25.32 \\
\hline 3 & 68.60 & 68.31 & 2.50 & 2.22 & 77.70 & 74.40 & 25.20 & 25.47 \\
\hline 4 & 69.10 & 69.13 & 2.40 & 2.35 & 58.90 & 59.92 & 25.30 & 25.03 \\
\hline 5 & 68.30 & 68.04 & 3.00 & 2.84 & 54.80 & 53.26 & 25.20 & 25.61 \\
\hline 6 & 65.90 & 65.97 & 3.00 & 3.07 & 62.10 & 64.89 & 26.50 & 26.37 \\
\hline 7 & 70.90 & 70.92 & 2.50 & 2.37 & 68.60 & 69.26 & 24.50 & 24.33 \\
\hline 8 & 70.80 & 70.45 & 2.10 & 1.75 & 63.70 & 64.58 & 24.80 & 24.94 \\
\hline 9 & 69.90 & 70.03 & 1.90 & 2.05 & 60.10 & 63.16 & 25.30 & 25.06 \\
\hline 10 & 68.80 & 69.0 & 2.20 & 2.34 & 63.10 & 60.76 & 25.30 & 25.34 \\
\hline 11 & 67.00 & 67.08 & 3.40 & 3.31 & 56.50 & 57.04 & 26.10 & 25.81 \\
\hline 12 & 70.50 & 70.74 & 1.80 & 2.18 & 69.20 & 69.39 & 24.40 & 24.49 \\
\hline 13 & 67.20 & 67.32 & 2.50 & 2.55 & 64.70 & 67.34 & 25.90 & 25.78 \\
\hline 14 & 67.90 & 68.10 & 2.30 & 2.54 & 68.00 & 66.09 & 25.80 & 25.72 \\
\hline 15 & 69.80 & 70.29 & 2.30 & 2.29 & 73.80 & 73.78 & 25.90 & 25.91 \\
\hline 16 & 70.40 & 70.29 & 2.30 & 2.29 & 73.80 & 73.78 & 25.90 & 25.91 \\
\hline 17 & 70.40 & 70.29 & 2.30 & 2.29 & 73.80 & 73.78 & 25.90 & 25.91 \\
\hline 18 & 70.40 & 70.29 & 2.30 & 2.29 & 73.80 & 73.78 & 25.90 & 25.91 \\
\hline 19 & 70.40 & 70.29 & 2.30 & 2.29 & 73.80 & 73.78 & 25.90 & 25.91 \\
\hline 20 & 70.40 & 70.29 & 2.30 & 2.29 & 73.80 & 73.78 & 25.90 & 25.91 \\
\hline
\end{tabular}

3) Grain hardness: The model fitted for Grain hardness (GH) was found to be significant and adequately sufficient to predict the strength of the parboiled milled rice (Table 3). The linear terms are negative except that of the soaking time. This indicated that increase in the initial soaking temperature of the paddy and the final moisture content of the paddy before milling may cause a reduction in the grain hardness of the milled rice and increase in the soaking time may improve the hardness of the grain. The significance of the individual terms of the model is shown in Tables 7 and the adequacy of the model is confirmed by $\mathrm{R}^{2}$ and $\mathrm{R}^{2}$ (adjusted) values of 0.94 and 0.89 respectively. The p-values for all the terms showed significance at $95 \%$ confidence level. The Residual plots are also shown in Figures 5 and 6.
TABLE 5. ANALYSIS OF VARIANCE (ANOVA) FOR THE FITTED QUADRATIC POLYNOMIAL MODEL FOR HEAD RICE YIELD DURING PARBOILING PROCESS

\begin{tabular}{|c|c|c|c|c|c|}
\hline $\begin{array}{c}\text { Source of } \\
\text { variation }\end{array}$ & $\begin{array}{c}\text { Degree of } \\
\text { freedom }\end{array}$ & $\begin{array}{c}\text { Sum of } \\
\text { Square }\end{array}$ & $\begin{array}{c}\text { Mean sum } \\
\text { of square }\end{array}$ & f-value & p-value \\
\hline Regression & 9 & 39.56 & 4.40 & 53.00 & 0.001 \\
\hline Linear & 3 & 18.29 & 6.10 & 73.51 & 0.000 \\
\hline Square & 3 & 14.64 & 4.48 & 58.87 & 0.001 \\
\hline Interaction & 3 & 6.63 & 2.21 & 26.63 & 0.000 \\
\hline Residual & 10 & 0.829 & 0.08 & $*$ & $*$ \\
\hline Total & 19 & 40.39 & $*$ & $*$ & $*$ \\
\hline
\end{tabular}




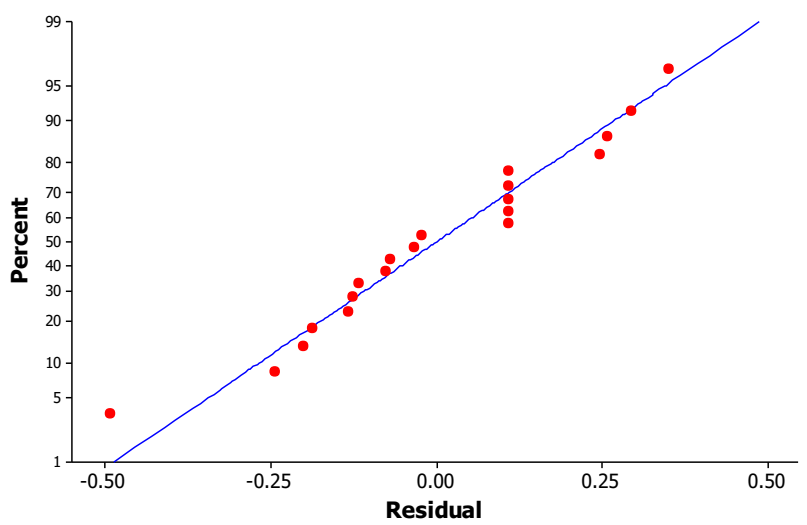

Fig. 1. Normal probability plot of the residual for HRY

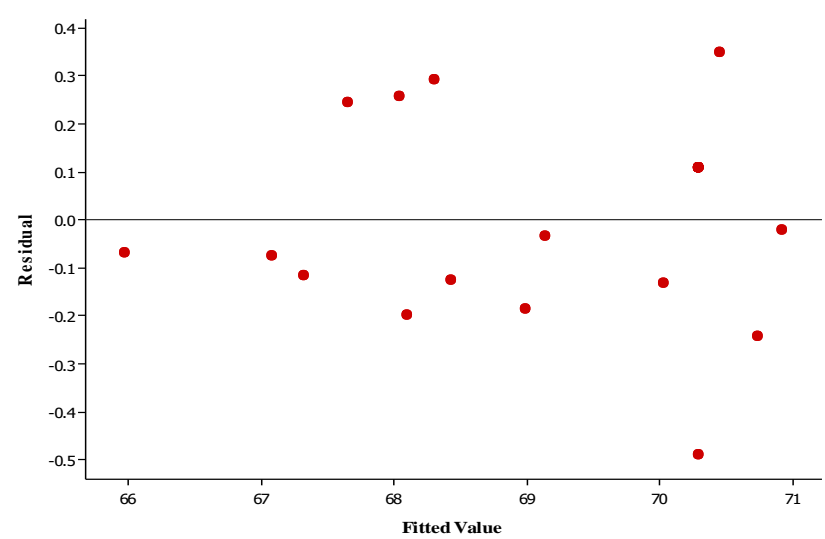

Fig. 2. Plot of residuals against fitted values for HRY

TABLE 6. ANALYSIS OF VARIANCE (ANOVA) FOR THE FITTED QUADRATIC POLYNOMIAL MODEL FOR BROKEN RICE RATIO DURING PARBOILING PROCESS

\begin{tabular}{|c|c|c|c|c|c|}
\hline $\begin{array}{l}\text { Source of } \\
\text { variation }\end{array}$ & $\begin{array}{c}\text { Degree of } \\
\text { freedom }\end{array}$ & $\begin{array}{c}\text { Sum of } \\
\text { Square }\end{array}$ & $\begin{array}{c}\text { Mean sum } \\
\text { of square }\end{array}$ & f-value & p-value \\
\hline Regression & 9 & 2.893 & 0.321 & 6.0 & 0.005 \\
\hline Linear & 3 & 1.65 & 0.550 & 10.27 & 0.002 \\
\hline Square & 3 & 0.50 & 0.166 & 3.11 & 0.076 \\
\hline Interaction & 3 & 0.74 & 0.248 & 4.63 & 0.028 \\
\hline Residual & 10 & 0.54 & 0.054 & $*$ & $*$ \\
\hline Total & 19 & 3.43 & $*$ & $*$ & $*$ \\
\hline
\end{tabular}

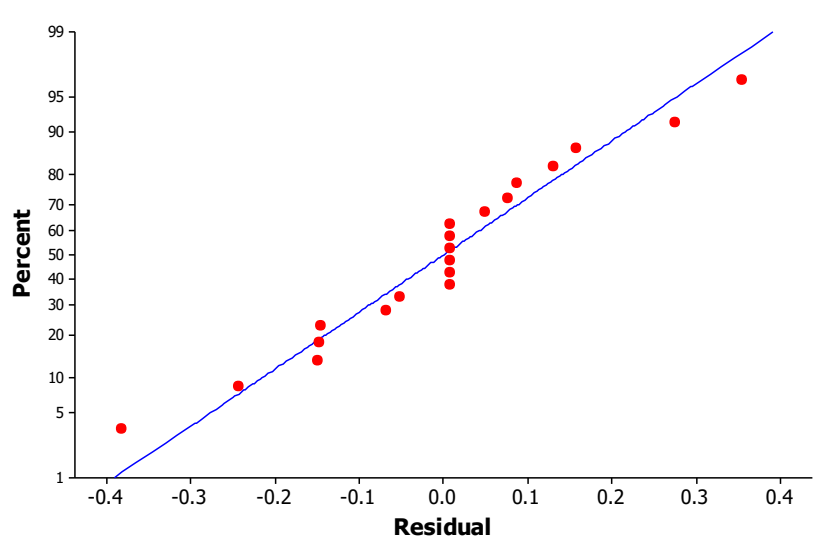

Fig 3. Normal probability plot of the residual for BRR

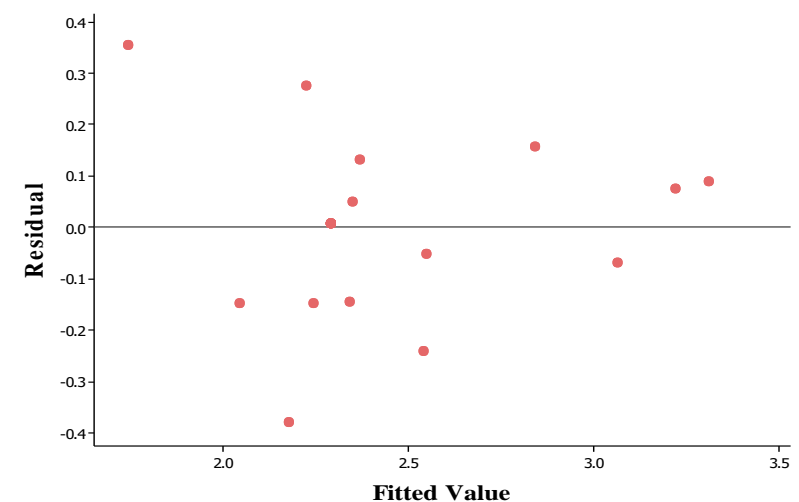

Fig. 4. Plot of residuals against fitted values for BRR

TABLE 7. ANALYSIS OF VARIANCE (ANOVA) FOR THE FITTED QUADRATIC POLYNOMIAL MODEL FOR GRAIN HARDNESS DURING PARBOILING PROCESS

\begin{tabular}{|c|c|c|c|c|c|}
\hline $\begin{array}{c}\text { Source of } \\
\text { variation }\end{array}$ & $\begin{array}{c}\text { Degree of } \\
\text { freedom }\end{array}$ & $\begin{array}{c}\text { Sum of } \\
\text { Square }\end{array}$ & $\begin{array}{c}\text { Mean sum } \\
\text { of square }\end{array}$ & f-value & p-value \\
\hline Regression & 9 & 833.096 & 92.566 & 17.68 & 0.000 \\
\hline Linear & 3 & 193.057 & 64.352 & 12.29 & 0.001 \\
\hline Square & 3 & 458.674 & 152.891 & 29.20 & 0.000 \\
\hline Interaction & 3 & 181.365 & 60.455 & 11.54 & 0.001 \\
\hline Residual & 10 & 52.366 & 5.327 & $*$ & $*$ \\
\hline Total & 19 & 885.462 & $*$ & $*$ & $*$ \\
\hline
\end{tabular}

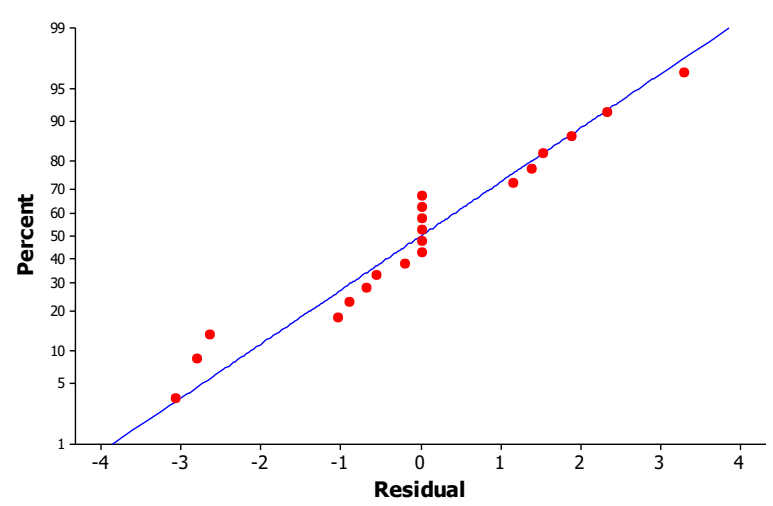

Fig. 5 Plot of residuals against fitted values for Grain hardness

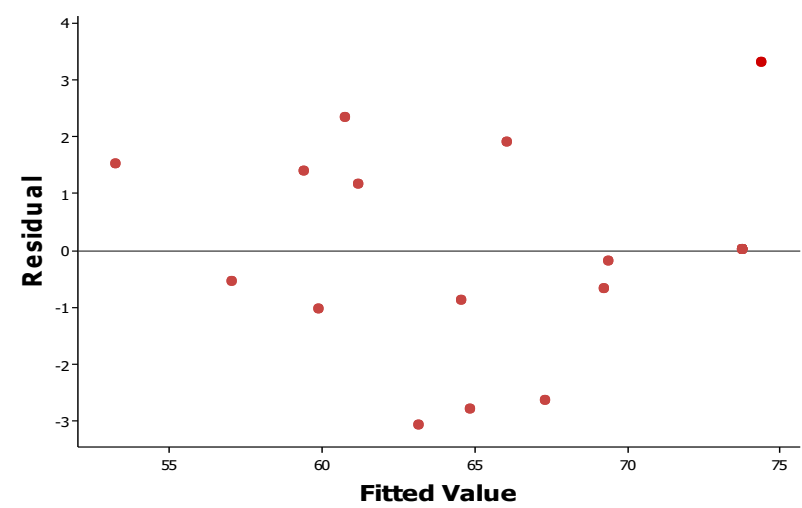

Fig. 6. Plot of residuals against fitted values for Grain hardness 
4) Grain colour: The models fitted for Grain colour as affected by the parboiling factors shows that increase in the soaking time of paddy may lead to reduced whiteness value and hence darker grains (Table 3). This is expected as soaking has been reported to cause discolouration due to enzymatic reactions and transfer of pigments into the grain [19]. According to [20], prolonged soaking activates enzymes that will influence the staining activities to discolour the rice kernels. However, increase in the initial soaking temperature may cause a corresponding increase in the whiteness value (lighter grain colour).

TABLE 8. ANALYSIS OF VARIANCE (ANOVA) FOR THE FITTED QUADRATIC POLYNOMIAL MODEL FOR GRAIN COLOUR DURING PARBOILING PROCESS

\begin{tabular}{|c|c|c|c|c|c|}
\hline $\begin{array}{c}\text { Source of } \\
\text { variation }\end{array}$ & $\begin{array}{c}\text { Degree of } \\
\text { freedom }\end{array}$ & $\begin{array}{c}\text { Sum of } \\
\text { Square }\end{array}$ & $\begin{array}{c}\text { Mean sum } \\
\text { of square }\end{array}$ & $\begin{array}{c}\mathrm{f}- \\
\text { value }\end{array}$ & $\begin{array}{c}\mathrm{p}- \\
\text { value }\end{array}$ \\
\hline Regression & 9 & 1.576 & 0.575 & 8.86 & 0.001 \\
\hline Linear & 3 & 2.197 & 0.732 & 11.28 & 0.002 \\
\hline Square & 3 & 1.756 & 0.585 & 9.01 & 0.003 \\
\hline Interaction & 3 & 1.224 & 0.408 & 6.28 & 0.011 \\
\hline Residual & 10 & 0.649 & 0.065 & $*$ & $*$ \\
\hline Total & 19 & 5.826 & $*$ & $*$ & $*$ \\
\hline
\end{tabular}

The normal probability plot of the residuals and the plot of the residuals versus the predicted response as shown in Figures 7 and 8 confirmed the adequacy of the model. The adequacy of the model is also confirmed by the $\mathrm{R}^{2}$ and $\mathrm{R}^{2}$ (adjusted) values of 0.89 and 0.79 respectively. The p-values for all the terms showed significance at $95 \%$ confidence level (Table 8 ).

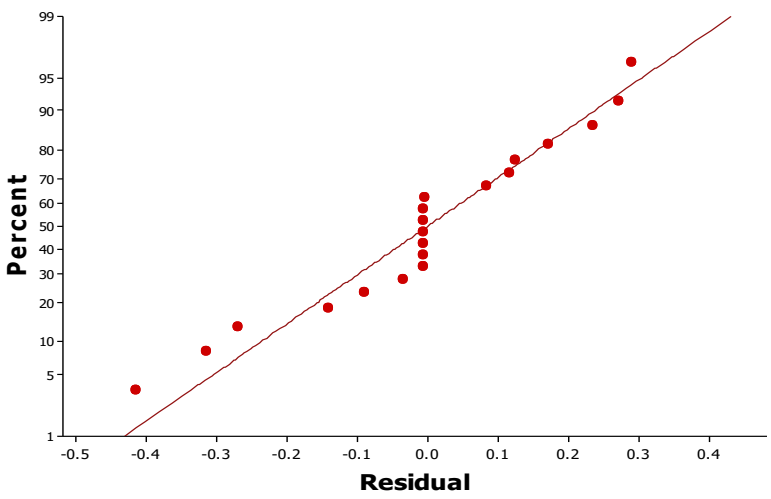

Fig. 7. Plot of residuals against fitted values for Grain colour

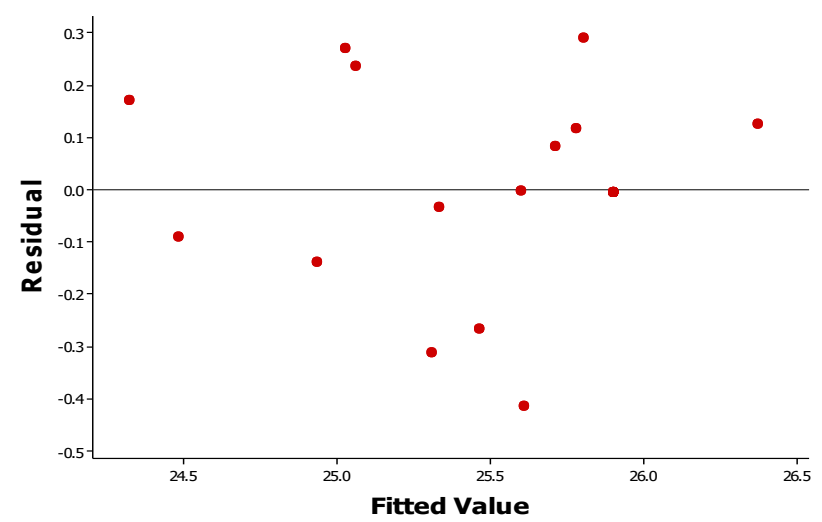

Fig. 8. Plot of residuals against fitted values for Grain colour

\section{Response Optimisation}

The results of the optimised responses of the physical properties of the parboiled milled rice as well as the criteria are as presented in Table 9 and the quality desirability in Figure 9.

TABLE 9. CRITERIA AND RESULTS OF OPTIMISATION OF PARBOILING CONDITIONS

\begin{tabular}{|c|c|c|c|}
\hline Response & Goal & Response & Desirability \\
\hline Head rice yield (\%) & Maximum & $70 \%$ & $100 \%$ \\
\hline Broken rice ratio (\%) & Minimum & $2.18 \%$ & $63.9 \%$ \\
\hline Grain hardness (N) & Maximum & $74.7 \mathrm{~N}$ & $89.5 \%$ \\
\hline Grain colour & Maximum & 25.8 & $59.2 \%$ \\
\hline
\end{tabular}

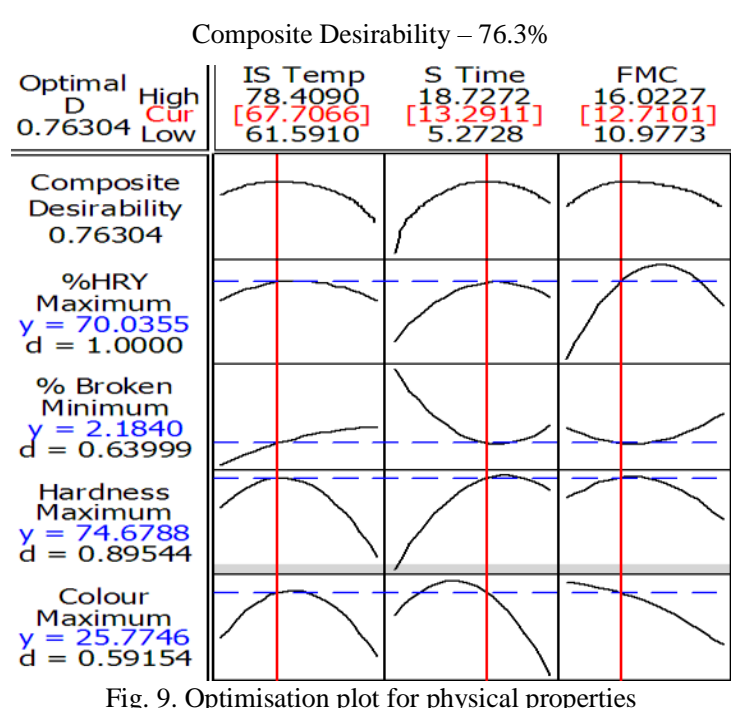

Fig. 9. Optimisation plot for physical propertie

From the optimisation result and plot (Figure 9), the optimum conditions for paddy parboiling for a desirable physical qualities of milled rice grain are Initial Soaking Temperature: $67.7^{\circ} \mathrm{C}$; Soaking Time: 13.3 hours, and Final Moisture Content: $12.7 \%$. These optimal conditions are expected to produce parboiled milled rice with: Head rice yield, 70\%; Broken rice ratio, 2.18\%; Grain hardness, $74.7 \mathrm{~N}$ and Grain colour, 25.8.

The individual desirability of the responses indicated that the optimal combinations of the factors as shown in Figure 9 is effective in maximizing the Head rice yield and the Grain hardness and also in minimizing the Broken rice ratio. The composite desirability of $76.3 \%$ (Table 9) showed how the settings optimize all the four quality responses when they are considered as objective response functions simultaneously [21].

\section{CONCLUSION}

It can be concluded that the optimum parboiling conditions for desirable physical qualities of FARO 52 rice variety are: Initial soaking temperature: $67.7^{\circ} \mathrm{C}$; Soaking time: $13 \mathrm{hrs} 18$ minutes and Final moisture content: $12.7 \%$. These optimal conditions are expected to produce parboiled milled rice with the following desired physical characteristics: Head rice yield, $70 \%$; Broken rice ratio, 2.18\%; Grain hardness, $74.7 \mathrm{~N}$ and Grain colour, 25.8. The composite desirability for the optimal settings is $76.3 \%$ and showed favorable results for all responses when considered simultaneously as objective response functions. 


\section{REFERENCES}

[1] Erhabor, P. O. I and Ojogho, O. (2011).Effect of quality on the demand for rice in Nigeria, Agricultural Journal. 6 (5), 207-212. 2011

[2] United States Department of Agriculture (USDA)..Nigeria grain and feed update..USDA Foreign Agricultural Service, Global Agricultural Information Network Report. November,/2014.

[3] Federal Ministry of Agriculture and Rural Development (FMARD). A guideline for RIPMAPP technology dissemination. Publication of Federal Ministry of Agriculture and Rural Developemt and the Japan International Cooperation Agency, JICA, March 2016.

[4] Danbaba, N., Anounye, J. C., Gana, A. S., Abo, M. E., Ukwungwu, M. $\mathrm{N}$. Grain quality characteristics of Ofada rice (Oryza sativa L.): Cooking and eating quality. International Food Research Journal. 18, 629-634. 2012

[5] Ogunbiyi, M. O. Assessment of postharvest handling and quality control practices of rice in North Central Nigeria: A case study of Lafia, Nasarawa State. Journal of Developments in Sustainable Agriculture Vol 6. No. 2: 143-163. 2011

[6] Bamidele, F. S., Abayomi, O. O., Esther, O. A. Economic analysis of rice consumption patterns in Nigeria. Journal of Agricultural Science Technology. 12, 1-11. 2010

[7] United States Agency for International Development (USAID). Global food security response: nigeria rice study. Attachment IV to the Global Food Security Response.West Africa Rice Value Chain Analysis. United State Agency for International Development. 2009

[8] Oko, A. O., Ubi, B. E. and Danbaba, N. Rice cooking quality and physico-chemical characteristics: a comparative analysis of selected local and newly introduced rice varieties in ebonyi state.: Food and Public Health. 2012, 2(1): 43-49. 2012.

[9] Sareepuang, K., Siriamornpun, S., Wiset, L. and Meeso, N. Effect of temperature on physical, chemical and cooking properties of parboiled fragrant rice. World Journal of Agricultural Sciences 4(4):409-415. 2008.

[10] Danbaba N., Nkama, I., Badau, M, H., Ukwungwu, M. N., Maji, A. T., Abo, M.E., Hauwawu H., K.. Fati, I. and Oko, A. O. Optimization of rice parboiling process for optimum head rice yield: a Response Surface Methodology (RSM) approach. .International Journal of Agriculture and Forestry 2014, 4(3): 154-165. 2014.

[11] Khurram Y., Chen K., Chen C. Adnan, A.,Yuping, H.,Chaudhry, A. and Zhang, X. (2017). The optimization and mathematical modeling of quality attributes of parboiled rice using a Response Surface Method, Journal of Food Quality, vol. 2017, Article ID 5960743, 2017. https://doi.org/10.1155/2017/5960743.

[12] Azami, M., Bahram, M., Nouri, S. and Naseri, A. A central composite design for the optimization of the removal of the azo dye, methyl orange, from waste water using the Fenton reaction. Journal of Serbian Chemical Society. 77 (2) 235-246. 2012.

[13] Ogunbiyi, M. O., Adejumo, B. A., Gbabo, A and Chinma, C. E Development of an improved mini rice paddy parboiler. Journal of Science, Technology, Mathematics and Education. 13(4) 37-44. December, 2017.

[14] Gbabo, A., Dauda, S.M. and Igbeka, J.C. Water absorption behaviour of milled parboiled rice in relationship with variety and some basic thermodynamics. AU J.T. 13(2): 101-106. 2009.

[15] Danbaba, N., Nkama, I. and Badau, M. H. Application of Response Surface Methodology (RSM) and Central Composite Design (CCD) to optimize minerals composition of rice-cowpea composite blends during extrusion cooking. International Journal of Food Science and Nutrition Engineering 2015, 5(1): 40-52.

[16] Fofana, M., Wanvoeke, J., Manful, J., Futakuchi, K., Van Mele, P. Zossou, E., Bléoussi, T. M. R. .Effect of improved parboiling methods on the physical and cooked grain characteristics of rice varieties in Benin. International Food Research Journal. 18, 715-721. 2011

[17] Roy, P., Orikasa, T., Okadome, H., Nakamura, N. and Shiina, T. Processing conditions, rice properties, health and environment. International Journal of Environmental Research and Public Health, 8(6), 1957-1976. 2011.

[18] Steppan, D.D., J. Werner, and R.P. Yeater. Essential regression and experimental design for chemists and engineers, http://www.jowerner.homepage.t-online.de/ERPref.html
[19] Kimura T., Bhattacharya, K.R. and Ali, S.Z. Discoloration characteristics of rice during parboiling (I): Effect of processing conditions on the colour intensity of parboiled rice. J. Jpn. Soc. Agric. Struct., 24, 23-30. 1993

[20] Ayamdoo, A. J., Demuyakor, B., Saalia, F. K. and Francis, A. Effect of varying parboiling conditions on the cooking and eating/sensory characteristics of Jasmine 85 and NERICA 14 rice varieties. American. Journal of Food Technology, 9: 1-14.2014

[21] Komaki, M. and Malakooti, B. Composite Desirability Function (CDF) Approach for Evolutionary Algorithm Parameter Tuning. Proceedings of the 2016 International Conference on Industrial Engineering and Operations Management, Detroit, Michigan, USA, September 23-25, 2016 